\title{
KINETIC BEHAVIOR OF SOME AZO DYES DECOLORIZATION BY VARIATION OF ZINC OXIDE AND TITANIUM DIOXIDE CONCENTRATIONS
}

\author{
Wallace J. C. da Silva, Natalia M. Monezi, Vanildo S. Leão Neto and Keiko Takashima* \\ Departamento de Química, Universidade Estadual de Londrina, 86057-970 Londrina - PR, Brasil
}

Recebido em 04/08/2017; aceito em 21/11/2017; publicado na web em 12/12/2017

\begin{abstract}
The decolorization of three monoazo dyes (acid orange 7, direct orange 34, and methyl orange), one diazo dye (direct yellow 86) and one tetraazo dye (direct red 80) were mediated by n-type semiconductors as $\mathrm{ZnO}$ and $\mathrm{TiO}_{2}$ under pseudo-first order conditions at $30{ }^{\circ} \mathrm{C}$. The decolorization rate constants of these azo dyes were determined, varying the semiconductor concentration for the majority of them from 1.0 to $10.0 \mathrm{~g} \mathrm{~L}^{-1}$. In general, the highest rate constants were displayed for $\mathrm{ZnO}$. This work elucidates that the decolorization capacity depends on the charge, structure, and adsorption of the azo dye on the semiconductor surface as well as the agglomeration of the photocatalyst particles.
\end{abstract}

Keywords: heterogeneous photocatalysis; $\mathrm{ZnO} ; \mathrm{TiO}_{2}$; first-order rate constant.

\section{INTRODUCTION}

Azo dyes are an important class of synthetic dyes, characterized by the presence of one or more azo groups $(-\mathrm{N}=\mathrm{N}-)$, bonded to a benzene or a naphthalene group. They represent about $50 \%$ of worldwide dye production and are widely used in a number of industries such as textile, paint, cosmetic, food, and plastic, with the textile industry being the largest consumer. ${ }^{1}$ Large amounts of these dyes remain in the effluent after the completion of the dyeing process. This leads to severe contamination of an aquatic system, because many of these compounds are considered carcinogenic and can produce toxic aromatic amines. ${ }^{2}$ Since these dyes are highly soluble in water, their removal from wastewater is difficult by conventional methods such as biodegradation, microfiltration, reverse osmosis and activated carbon adsorption. ${ }^{3-5}$

Heterogeneous photocatalysis, mediated by an n-type semiconductor as $\mathrm{TiO}_{2}$ and $\mathrm{ZnO}$, has been considered as a cost effective alternative for the purification of dye containing wastewater. ${ }^{6-8}$ In this process, the semiconductor absorbs radiation with higher energy than band-gap, promoting the valence band electrons to the conduction band, creating an electron-hole pair. The valence band hole can either receive an electron from the adsorbed dye or oxidize the adsorbed water or a hydroxyl ion in order to convert it to hydroxyl radical, $\bullet \mathrm{OH}$. This radical is considered non-selective, presents a short lifetime and high oxidation potential $(2.8 \mathrm{~V})$ that can mineralize organic substances. On the other hand, the electrons promoted to the conduction band are transferred to the adsorbed oxygen molecules to convert it into ion-radical superoxide, $\bullet \mathrm{O}_{2}$, When it is protonated, generates hydrogen peroxide and contributes to the contaminant oxidation. ${ }^{9}$

The optimization of the photocatalytic process for several organic contaminants degradation has been carried out, varying the semiconductor concentration, $\mathrm{pH}$, oxidants addition such as peroxides, persulfates, among others. ${ }^{10-14}$ In general, the degradation rate constant of the contaminants increases with $\mathrm{TiO}_{2}$ concentration in heterogeneous photocatalysis. So, it has been considered that the larger the number of active sites to dye adsorption, as well the interaction with electron-hole pairs, the larger the degradation efficiency will be. Thus, the $\mathrm{TiO}_{2}$ oxidation efficiency for a fixed substrate concentration

*e-mail: keiko.takashima@gmail.com is larger, the larger the number of semiconductor particles. Conversely, when this concentration is continuously increased, the distance between particles decreases and the suspension becomes opaque. This makes the light passage difficult and decreases the decolorization rate constant. ${ }^{15-18}$ On the other hand, the decolorization rate constant of direct red 23 diazo dye enhanced when the semiconductor concentration was increased from 1.0 to $7.0 \mathrm{~g} \mathrm{~L}^{-1}$ giving a positive inflection in $5.0 \mathrm{~g} \mathrm{~L}^{-1}$, mediated by zinc oxide at $30{ }^{\circ} \mathrm{C} .{ }^{19} \mathrm{In}$ general, the rate constant of the azo dye decolorization increases until a certain $\mathrm{TiO}_{2}$ concentration and decreases due to the agglomeration of these particles, hindering the radiation passage. Considering the results to the DR23 decolorization in $\mathrm{ZnO}$ medium ${ }^{19}$ and the difference with respect to $\mathrm{TiO}_{2},{ }^{20-22}$ we investigated the unusual kinetic behavior in $\mathrm{ZnO}$ based on photocatalysis by comparing the decolorization kinetic using $\mathrm{ZnO}$ and $\mathrm{TiO}_{2}$ in a wide range of concentrations. Thus, we studied the decolorization of three monoazo dyes (acid orange 7 , direct orange 34 , and methyl orange), one diazo dye (direct yellow 86) and one tetraazo dye (direct red 80) (Figure 1) varying the concentration of $\mathrm{ZnO}$ and $\mathrm{TiO}_{2}$ at $30{ }^{\circ} \mathrm{C}$.

\section{EXPERIMENTAL SECTION}

The monoazo dyes acid orange 7 (AO7; C.I. 15510; $\varepsilon=2.46 \times 10^{4} \mathrm{~cm}^{-1} \mathrm{~mol}^{-1} \mathrm{~L}$ at $483 \mathrm{~nm}$ ) and direct orange 34 (DO34; C.I. $40215 ; \varepsilon=2.60 \times 10^{4} \mathrm{~cm}^{-1} \mathrm{~mol}^{-1} \mathrm{~L}$ at $\left.415 \mathrm{~nm}\right)$, direct yellow 86 diazo dye (DY86; C.I. 29325; $\varepsilon=8.51 \times 10^{4} \mathrm{~cm}^{-1} \mathrm{~mol}^{-1} \mathrm{~L}$ at $370 \mathrm{~nm}$ ) and direct red 80 tetraazo dye (DR80; C.I. 35780; $\varepsilon=2.70 \times 10^{4} \mathrm{~cm}^{-1} \mathrm{~mol}^{-1} \mathrm{~L}$ at $512 \mathrm{~nm}$ ) were attained from Chimical and the methyl orange monoazo dye was purchased from Reagen (MO; CI 13025; $\varepsilon=3.15 \times 10^{4} \mathrm{~cm}^{-1} \mathrm{~mol}^{-1} \mathrm{~L}$ at $462 \mathrm{~nm}$ ). The molar absorption coefficient, $\varepsilon$, of the azo dyes was determined experimentally and the initial concentrations were $8.0 \times 10^{-5} \mathrm{~mol} \mathrm{~L}^{-1}(\mathrm{AO} 7), 2.5 \times 10^{-5} \mathrm{~mol} \mathrm{~L}^{-1}$ (DO34), $8.0 \times 10^{-5} \mathrm{~mol} \mathrm{~L}^{-1}(\mathrm{MO}), 7.0 \times 10^{-5} \mathrm{~mol} \mathrm{~L}^{-1}$ (DY86), and $8.0 \times 10^{-5} \mathrm{~mol} \mathrm{~L}^{-1}(\mathrm{DR} 80)$. The initial concentration of each azo dye was determined from the molar absorption coefficient to get the initial absorbance in approximately 2.0. The adsorption and irradiation of the suspension were performed at natural $\mathrm{pH}$ inside a wood chamber $(50 \times 50 \times 50 \mathrm{~cm})$, covered internally with an aluminum foil and frontal part closed with a black fabric curtain, using a borosilicate glass reactor $(200 \mathrm{~mL})$ with a double wall for water circulation at $30.0 \pm 0.1{ }^{\circ} \mathrm{C}$ (Quimis Q214M2). 
<smiles>CN(C)c1ccc(N=Nc2ccc(S(=O)(=O)[O-])cc2)cc1</smiles>

(a)<smiles>CS(=O)(=O)c1ccc(N=Nc2ccc(N)cc2)cc1</smiles>

(b)

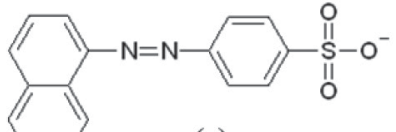

(c)<smiles>Cc1cc(Nc2nc(NCCO)nc(Nc3cccc(N=Nc4cc([O-])c5cccc(S(=O)(=O)[O-])c5c4)c3)n2)ccc1N=Nc1cc([O-])c2cccc(S(=O)(=O)[O-])c2c1</smiles><smiles>O=C(Nc1ccc2cc([N+](=O)[O-])c(N=Nc3ccc(N=Nc4ccc([O-])cc4)cc3[S+](=O)[O-])cc2c1)Nc1ccc2c(O)c(NC(=O)Nc3ccc(N=Nc4ccc([S+](=O)[O-])cc4)cc3[S+](=O)[O-])ccc2c1</smiles>

(e)

Figure 1. Structural formula of the azo dyes (a) direct orange 34, (b) methyl orange, (c) acid orange 7, (d) direct yellow 86, and (e) direct red 80

The adsorption equilibrium of the azo dye in the suspension, formed by $\mathrm{ZnO}$ (Nuclear, PA) or $\mathrm{TiO}_{2} \mathrm{P} 25$ (Degussa, PA) in a volume of $150 \mathrm{~mL}$, was obtained leaving it in the dark in a variable time under constant stirring (600 rpm, Fisatom) at $30.0 \pm 0.1{ }^{\circ} \mathrm{C}$ (Quimis Q214M2). Aliquots of $1.0 \mathrm{~mL}$ were removed at predetermined times, filtered (Millipore, $0.22 \mu \mathrm{m}$ ) and UV-Vis spectra were registered (Hitachi U-3000) until the absorbance remains constant. Subsequently, Hg vapor lamp without bulb (Osram 125 W, 220 V) horizontally positioned $15 \mathrm{~cm}$ above the glass reactor was lighted and $1.0 \mathrm{~mL}$ aliquots were withdrawn as a function of irradiation time, filtered, and spectra were registered to determine the decolorization rate constant. The azo dyes photolysis was not carried out, due to their high stability under UV radiation.

The decolorization rate constants, $k_{o b s}$, were determined under pseudo-first order conditions at $30^{\circ} \mathrm{C}$, that is, using a large catalyst excess with respect to the azo dye, from $\ln A_{t}=-k_{o b s} t+\ln A_{0}$, where $A_{t}$ is the absorbance at $\mathrm{t}$ time and $A_{0}$ at zero time. ${ }^{23}$ The decolorization of the chromophore groups and degradation of aromatic groups occurred simultaneously by the decrease of the UV-Vis bands relative to these two chemical groups.

In addition, semi-empirical calculations were performed for DR80 dye using the Spartan software through the Hartree-Fock theoretical method and basis set $3-21 G^{*},{ }^{24}$ in order to obtain the dipole moment value and atomic charge.

The characterization of $\mathrm{ZnO}$ (Nuclear) was carried out previously ${ }^{25}$ by X-ray diffraction (XRD), diffuse reflectance (DR) and Energy Dispersive X-Ray Diffraction (EDXRF). XRD showed a wurtzite crystalline structure; the band-gap energy of $3.16 \mathrm{eV}$ was determined by DR using the Tauc model, and the purity, verified by EDX-RF. Zielinska et al. characterized $\mathrm{TiO}_{2}(\mathrm{P} 25$, Degussa) by X-ray diffraction (XRD), diffuse reflectance (DR) and other techniques. XRD showed peaks of anatase and rutile, in which the anatase peaks presented more intensity, the band-gap energy of $3.14 \mathrm{eV}$ was determined by DR according to the equation $\mathrm{E}_{\mathrm{g}}=\mathrm{h} \mathrm{c} / \lambda .{ }^{26}$

\section{RESULTS AND DISCUSSION}

Three monoazo dyes were more susceptible to the oxidation by
$\mathrm{ZnO}$ in comparison to $\mathrm{TiO}_{2}$. From these, $\mathrm{AO} 7\left(8.0 \times 10^{-5} \mathrm{~mol} \mathrm{~L}^{-1}\right)$ was more reactive in both semiconductors, followed by DO34 $\left(2.5 \times 10^{-5} \mathrm{~mol} \mathrm{~L}^{-1}\right)$ and lastly, $\mathrm{MO}\left(8.0 \times 10^{-5} \mathrm{~mol} \mathrm{~L}^{-1}\right)$ as shown in Figure 2. DO34 decolorization rate constant enhanced linearly around six times (correlation coefficient, $r=0.976$ ) from $1.65 \times 10^{-2}$ to $9.36 \times 10^{-2} \mathrm{~min}^{-1}$, when the concentration of $\mathrm{ZnO}$ was varied from 1.0 to $10.0 \mathrm{~g} \mathrm{~L}^{-1}$ (Figure 2a). Similarly, $k_{o b s}$ of MO doubled from $3.15 \times 10^{-2}$ to $6.36 \times 10^{-2} \mathrm{~min}^{-1}(r=0.983)$ (Figure $2 \mathrm{~b}$ ). This means that the reaction orders for $\mathrm{ZnO}$ varying from 1.0 to $10.0 \mathrm{~g} \mathrm{~L}^{-1}$ were equivalent to 0.7 and 0.3 respectively in the decolorization of DO34 $\left(2.5 \times 10^{-5} \mathrm{~mol} \mathrm{~L}^{-1}\right)$ and $\mathrm{MO}\left(8.0 \times 10^{-5} \mathrm{~mol} \mathrm{~L}^{-1}\right)$ monoazo dyes. The structures of both dyes are distinguished by the functional group bonded to the ring, that is, amino group in DO34 and dimethylamino in MO (Figures 1a and 1b), suggesting a better adsorption affinity to DO34. This explains the higher reaction order in the presence of DO34 solution and consequently the larger rate constant enhancement, when mediated by $\mathrm{ZnO}$. Conversely, the reaction order resulted in 0.6 when $\mathrm{ZnO}$ concentration was increased from 1.0 to $3.0 \mathrm{~g} \mathrm{~L}^{-1}$ in $\mathrm{AO} 7$ solution, enhancing $k_{\text {obs }}$ from $5.61 \times 10^{-2}$ to $8.11 \times 10^{-2} \mathrm{~min}^{-1}$. The observed rate constant continued to increase linearly $(r=0.978)$ from 3.0 to $10.0 \mathrm{~g} \mathrm{~L}^{-1}$ of $\mathrm{ZnO}$ with a less pronounced slope, giving a reaction order of 0.1 as shown in Figure 2c. So, the largest decolorization rate constant obtained for $\mathrm{AO} 7$ is attributed to the naphthalene group (Figure 1c), which could delocalize a reasonable amount of negative charge density, becoming easier the approximation on $\mathrm{ZnO}$ or $\mathrm{TiO}_{2}$ surface.

Otherwise, when 1.0 and $2.0 \mathrm{~g} \mathrm{~L}^{-1}$ of $\mathrm{TiO}_{2}$ were used in DO34 solutions, the rate constants were equal to $2.32 \times 10^{-2}$ and $3.36 \times 10^{-2} \mathrm{~min}^{-1}$, whose values were larger with respect to $\mathrm{ZnO}$ medium (Figure 2). This was attributed to the larger DO34 adsorption on $\mathrm{TiO}_{2}$ surface than on $\mathrm{ZnO}$, since the initial DO34 absorbance $\left(2.5 \times 10^{-5} \mathrm{~mol} \mathrm{~L}^{-1}\right)$ decreased by 1.25 for $\mathrm{TiO}_{2}$ and 0.37 for $\mathrm{ZnO}$ after $30 \mathrm{~min}$ in the dark at $30^{\circ} \mathrm{C}$. When 3.0 and $4.0 \mathrm{~g} \mathrm{~L}^{-1}$ of $\mathrm{TiO}_{2}$ were used, there was a $k_{o b s}$ decrease trend from $3.22 \times 10^{-2}$ to $3.13 \times 10^{-2} \mathrm{~min}^{-1}$ (Figure 2a), ascribed to the obstruction of the radiation passage, caused by the agglomeration of the semiconductor particles. ${ }^{27}$ Similarly, $k_{o b s}$ values of $\mathrm{MO}$ on $\mathrm{TiO}_{2}$ (Figure $2 b$ ) were lower than on $\mathrm{ZnO}$, which presented analogous behavior of $\mathrm{DO} 34$ in $\mathrm{TiO}_{2}$ one, that is, from $1.64 \times 10^{-2} \mathrm{~min}^{-1}$ in $1.0 \mathrm{~g} \mathrm{~L}^{-1}$ to $2.78 \times 10^{-2} \mathrm{~min}^{-1}$ in $5.0 \mathrm{~g} \mathrm{~L}^{-1}$ 

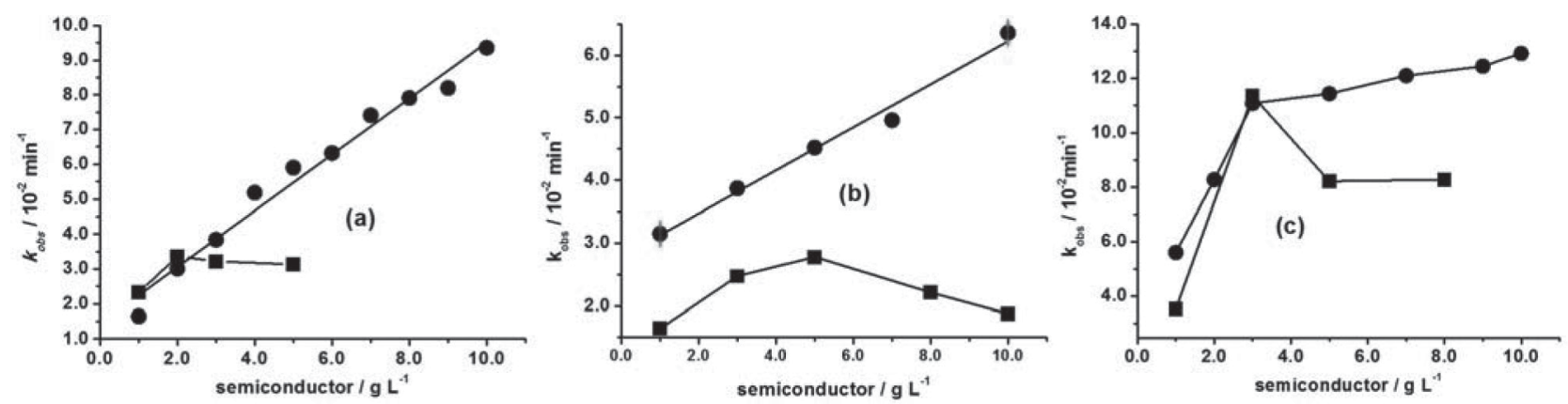

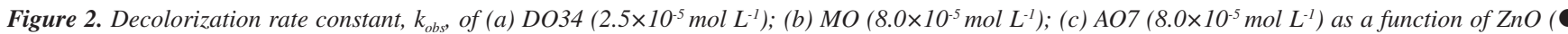
and $\mathrm{TiO}_{2}(\mathbf{\square})$ at $30{ }^{\circ} \mathrm{C}$

and declined to $1.88 \times 10^{-2} \mathrm{~min}^{-1}$ in $10.0 \mathrm{~g} \mathrm{~L}^{-1}$. By the same reason, this low reactivity of $\mathrm{MO}$ was attributed to the lower partial negative charge with respect to DO34 as mentioned above. Moreover, when $\mathrm{TiO}_{2}$ concentration was varied from 1.0 to $3.0 \mathrm{~g} \mathrm{~L}^{-1}$ the rate constant for AO7 increased three times from $3.52 \times 10^{-2}$ to $11.36 \times 10^{-2} \mathrm{~min}^{-1}$. In $3.0 \mathrm{~g} \mathrm{~L}^{-1} \mathrm{TiO}_{2} k_{\text {obs }}$ was very similar to $\mathrm{ZnO}$, however, when the concentration was increased to 5.0 and $8.0 \mathrm{~g} \mathrm{~L}^{-1}$ the rate constant decreased to about $8.2 \times 10^{-2} \mathrm{~min}^{-1}$ ascribed, in this case, to the obstruction of the passage of light by the suspension. There are very few researches about the kinetic behavior of azo dyes decolorization varying the semiconductor concentrations.

Danwittayakul, Jaisai, Koottatep, and Dutta ${ }^{28}$ investigated the MO decolorization of $32 \%$ after $3 \mathrm{~h} \mathrm{UV}$ irradiation in $\mathrm{ZnO}$ nanorods on polyester fiber. Alzahrani ${ }^{29}$ studied the decolorization of methyl orange $\left(100 \mathrm{mg} \mathrm{L}^{-1}\right)$ in a $\mathrm{ZnO}$ nanopowder $\left(0.5 \mathrm{~g} \mathrm{~L}^{-1}\right)$ at $25^{\circ} \mathrm{C}$ obtaining a rate constant of $2.4 \times 10^{-3} \mathrm{~min}^{-1}\left(\mathrm{R}^{2}=0.977\right)$. Hamadanian, Sarabi, Mehra, and Jabbari ${ }^{30}$ worked with $\mathrm{TiO}_{2}\left(1.0 \mathrm{~g} \mathrm{~L}^{-1}\right)$ doped with several $\mathrm{Cr}^{3+}$ concentrations. From these, the highest photoactivity was obtained when it was used $5 \% \mathrm{Cr}^{3+}$. Daneshvar, Rasoulifard, Khataee, and Hosseinzadeh ${ }^{31}$ investigated AO7 $\left(0.02 \mathrm{~g} \mathrm{~L}^{-1}\right)$ decolorization in $\mathrm{ZnO}$ medium, varying the catalyst concentration from 0.1 to $0.2 \mathrm{~g} \mathrm{~L}^{-1}$ and measuring the decolorization percentage with no control of temperature. Zhang, Sunb, Li, and Wang ${ }^{32}$ decolorized AO7 (0.1 $\left.\mathrm{g} \mathrm{L}^{-1}\right)$ in a suspension containing $\mathrm{TiO}_{2} 0.5 \mathrm{~g} \mathrm{~L}^{-1}$ and calculated the rate constant $\left(2.12 \times 10^{-2} \mathrm{~min}^{-1}\right)$ at $38 \pm 1{ }^{\circ} \mathrm{C}$. There are few papers about the DO34 decolorization in $\mathrm{ZnO}$ and $\mathrm{TiO}_{2}$ media. Among them, Niehues, Scarmínio, and Takashima ${ }^{33}$ investigated the DO34 decolorization percentage in $\mathrm{TiO}_{2}$ medium at $30{ }^{\circ} \mathrm{C}$ after $240 \mathrm{~min}$ UV irradiation by the $2^{5}$ factorial design.

Unlike monoazo dyes, the DY86 diazo dye decolorization was slower in $\mathrm{ZnO}$ in comparison to $\mathrm{TiO}_{2}$. For DY86, the adsorption was systematically lower in $\mathrm{ZnO}$. For example, the absorbance of DY86 $\left(7.0 \times 10^{-5} \mathrm{~mol} \mathrm{~L}^{-1}\right)$ decreased by 0.223 in $\mathrm{ZnO} 5.0 \mathrm{~g} \mathrm{~L}^{-1}$, whereas in $\mathrm{TiO}_{2}$ by 2.095 after 30 min adsorption in the dark at $30{ }^{\circ} \mathrm{C}$. Figure 3 shows that the $k_{o b s}$ for DY86 increased gradually from $\mathrm{ZnO} 1.0 \mathrm{~g} \mathrm{~L}^{-1}\left(1.85 \times 10^{-2} \mathrm{~min}^{-1}\right)$ to $14.0 \mathrm{~g} \mathrm{~L}^{-1}\left(3.51 \times 10^{-2} \mathrm{~min}^{-1}\right)$. On the other hand, $k_{o b s}$ increased from $1.85 \times 10^{-2} \mathrm{~min}^{-1}\left(1.0 \mathrm{~g} \mathrm{~L}^{-1}\right)$ to $8.57 \times 10^{-2} \mathrm{~min}^{-1}\left(5.0 \mathrm{~g} \mathrm{~L}^{-1}\right)$ in $\mathrm{TiO}_{2}$ medium and it was three times greater than $\mathrm{ZnO}\left(2.56 \times 10^{-2} \mathrm{~min}^{-1}\right)$ in the same concentration. This kinetic behavior was attributed to the high adsorption capacity of this azo dye in $\mathrm{TiO}_{2}$. Nevertheless, in $\mathrm{TiO}_{2} 8.0 \mathrm{~g} \mathrm{~L}^{-1}, k_{\text {obs }}$ decreased to $4.45 \times 10^{-2} \mathrm{~min}^{-1}$, attributed to the obstruction of radiation passage through the suspension, as above mentioned. Zhang et al. reported the only work about DY86 decolorization in $\mathrm{TiO}_{2}$ suspension, using $4.0 \mathrm{~g} \mathrm{~L}^{-1}$, under pseudo-second-order conditions at $25^{\circ} \mathrm{C} .{ }^{34}$ This means that the comparison is not possible with our results, since we worked at pseudo-first-order conditions at $30^{\circ} \mathrm{C}$.

Similar to DY86 diazo dye, the DR80 tetraazo dye $\left(8.0 \times 10^{-5} \mathrm{~mol} \mathrm{~L}^{-1}\right)$ showed higher reactivity in the $\mathrm{TiO}_{2}$ medium

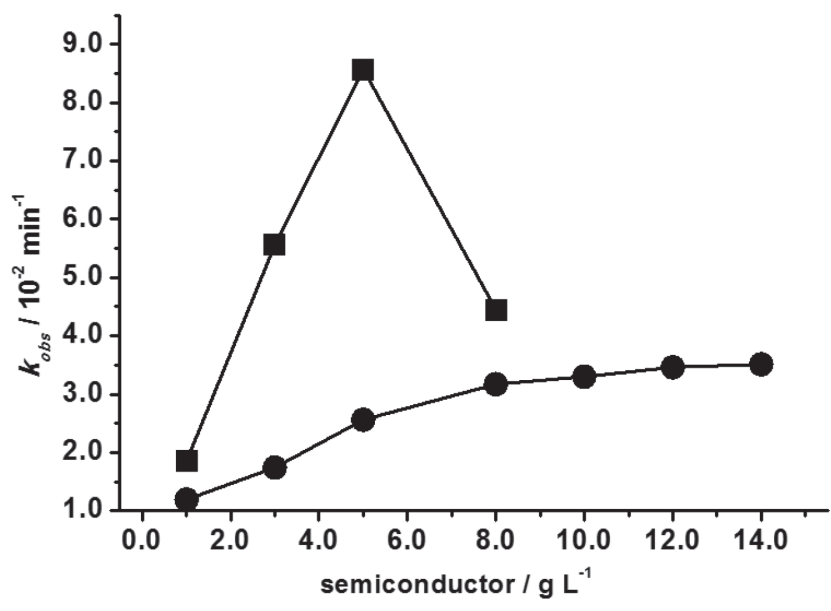

Figure 3. Decolorization rate constant, $k_{\text {obs }}$, of DY86 $\left(7.0 \times 10^{-5} \mathrm{~mol} \mathrm{~L}^{-1}\right)$ as a function of $\mathrm{ZnO}(\mathbf{O})$ and $\mathrm{TiO}_{2}(\mathbf{\square})$ at $30^{\circ} \mathrm{C}$

compared to $\mathrm{ZnO}$, displaying the largest $k_{o b s}$ values with respect to all other azo dyes. This occurs due to six sulfonate groups in DR80 (Figure 1e) that makes easier the adsorption on the surfaces of the semiconductors. According to the Figure 1d, DY86 has a triazine ring whose nitrogen atoms have p-orbitals that could generate resonance with three nitrogen atoms adjacent and stabilize the molecular structure, decreasing the reactivity. Even though four sulfonate groups are present in the structure, only two are used in the adsorption, because the other two are not in the same plane and so, the approximation becomes more difficult. Concentration of $\mathrm{ZnO}$

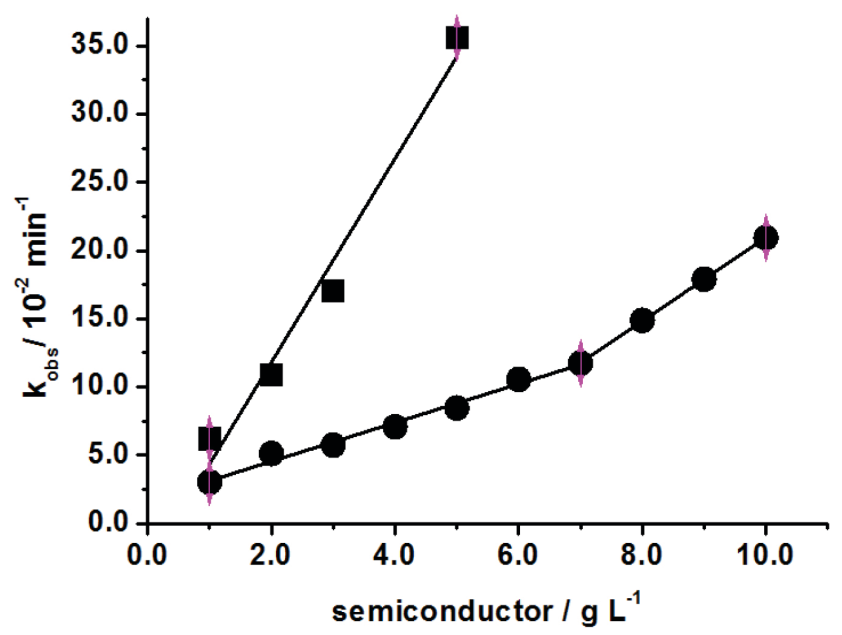

Figure 4. Decolorization rate constant, $k_{\text {obs }}$, of DR80 $\left(8.0 \times 10^{-5} \mathrm{~mol} \mathrm{~L}^{-1}\right)$ as a function of $\mathrm{ZnO}(\mathbf{O})$ and $\mathrm{TiO}_{2}(\mathbf{\square})$ at $30^{\circ} \mathrm{C}$ 
was varied from 1.0 to $10.0 \mathrm{~g} \mathrm{~L}^{-1}$ at $30^{\circ} \mathrm{C}$ in DR80 the $k_{\text {obs }}$ increased linearly from $3.03 \times 10^{-2}$ to $20.93 \times 10^{-2} \mathrm{~min}^{-1}$ with a positive inflection in $7.0 \mathrm{~g} \mathrm{~L}^{-1}$ with correlation coefficients of $0.994\left(1.0\right.$ to $\left.7.0 \mathrm{~g} \mathrm{~L}^{-1}\right)$ and 0.999 ( 7.0 to $10.0 \mathrm{~g} \mathrm{~L}^{-1}$ ) respectively, as shown in Figure 4.

Thus, the reaction orders with respect to the $\mathrm{ZnO}$ concentration were equivalent to 0.7 and 1.6 in DR80 solution. Our research group found similar behavior when direct red 23 diazo dye decolorization was also mediated by $\mathrm{ZnO}$, resulting in reaction orders respectively equal to 0.6 and 2.9. ${ }^{19}$ This behavior may be occurred, unlikely from $\mathrm{TiO}_{2}$, because the $\mathrm{ZnO}$ particles do not agglomerate even in higher concentrations, acquiring colloidal or nanoparticles characteristics, causing change in the reaction order. Therefore, the small particles of $\mathrm{ZnO}$ allow the radiation permeation in all the directions of the suspension. We verified this in qualitative experiments passing the radiation through the both suspensions. Due to the particles agglomeration in $\mathrm{TiO}_{2}$ medium, the radiation was absorbed in the first surface portions and the non-absorbed radiation was reflected to the out of the suspension. On the other hand, the particles did not suffer agglomeration in $\mathrm{ZnO}$ medium and because of this, the non-absorbed radiation passed through the suspension resulting in a higher photocatalytical efficiency. Conversely, the $\mathrm{TiO}_{2}$ concentration was varied only from $1.0 \mathrm{~g} \mathrm{~L}^{-1}\left(6.20 \times 10^{-2} \mathrm{~min}^{-1}\right)$ to $5.0 \mathrm{~g} \mathrm{~L}^{-1}$ $\left(35.31 \times 10^{-2} \mathrm{~min}^{-1}\right)$ with $\mathrm{r}=0.966$, due to the total adsorption of DR80 $\left(8.0 \times 10^{-5} \mathrm{~mol} \mathrm{~L}^{-1}\right)$ in $\mathrm{TiO}_{2} 6.0 \mathrm{~g} \mathrm{~L}^{-1}$ for $20 \mathrm{~min}$ at $30{ }^{\circ} \mathrm{C}$ in the dark. In this way, the DR80 decolorization rate constant in $\mathrm{TiO}_{2} 5.0 \mathrm{~g} \mathrm{~L}^{-1}$ was four times higher in relation to the same conditions using $\mathrm{ZnO}$ $\left(8.46 \times 10^{-2} \mathrm{~min}^{-1}\right)$. We investigated the decolorization rate constant for DR80 in similar conditions, ${ }^{25}$ obtaining $5.45 \times 10^{-2} \mathrm{~min}^{-1}$ for $8.0 \times 10^{-5} \mathrm{~mol} \mathrm{~L}^{-1} \mathrm{DR} 80$ in $1.5 \mathrm{~g} \mathrm{~L}^{-1} \mathrm{ZnO}$ suspension, whose value was analogous to the $k_{o b s}$ obtained in this work. The only reference found in the literature for this dye in $\mathrm{TiO}_{2}$ was carried out by Tsuji et al that investigated the $1.0 \times 10^{-4} \mathrm{~mol} \mathrm{~L}^{-1} \mathrm{DR} 80$ and other several azo dyes decolorization degree in $\mathrm{TiO}_{2}$ thin films. ${ }^{35}$

In order to understand the reason of the rate constant increase with $\mathrm{ZnO}$ concentration enhancement, semi-empirical calculations were carried out to determine the charge densities of the constituent atoms and the molecule dipole moment. ${ }^{24}$ The oxygen atoms charge densities are shown in Table 1 . The dipole moment of 7.84 D was calculated and located on the $\mathrm{C}=\mathrm{O}$ bond. The negative charges densities are located in the oxygen atoms of the six sulfonate groups (O3 to $\mathrm{O} 17$ and $\mathrm{O} 19$ to $\mathrm{O} 21$ ), in $\mathrm{OH}$ bonded to the naphthalene rings (O1 and $\mathrm{O} 2)$ and in the carbonyl oxygen (O18). The nitrogen atoms did not show significant negative charge density, that is, the nitrogen atoms charge is practically neutral. Theoretical results obtained for DR80 suggest that the adsorption occurs by oxygen atoms, and due the high negative charge of DR80, this leads to a higher physical adsorption on both semiconductors surface. This occurs due to the positive charge on the catalysts surface, elucidated by experimental $\mathrm{pH}$ of $\sim 7.3(\mathrm{ZnO})$ and $~ 4.3\left(\mathrm{TiO}_{2}\right)$, taking into account that $\mathrm{ZnO}$ has a $\mathrm{pH}_{\mathrm{pzc}}$ of 11.0 and $\mathrm{TiO}_{2}$ of 6.2 .

\section{CONCLUSIONS}

From these results, $\mathrm{TiO}_{2}$ particles showed more facility to agglomerate in comparison to $\mathrm{ZnO}$. It was verified that $\mathrm{ZnO}$ particles did not suffer agglomeration in the decolorization of all the azo dyes even at high concentrations like $14.0 \mathrm{~g} \mathrm{~L}^{-1}$ for DY86 and $10 \mathrm{~g} \mathrm{~L}^{-1}$ for other azo dyes as DO34, MO, AO7, and DR80 at $30{ }^{\circ} \mathrm{C}$. DY86 diazo dye and DR80 tetraazo dye presented a larger reactivity in $\mathrm{TiO}_{2}$ suspension, meanwhile MO, DO34, and AO7 monoazo dyes were more reactive in $\mathrm{ZnO}$ medium. This suggests that the structure size of the azo dye interferes in the interaction with the semiconductor type. The azo dyes decolorization rate constant was dependent on the azo
Table 1. Partial charge density of oxygen atom of DR80

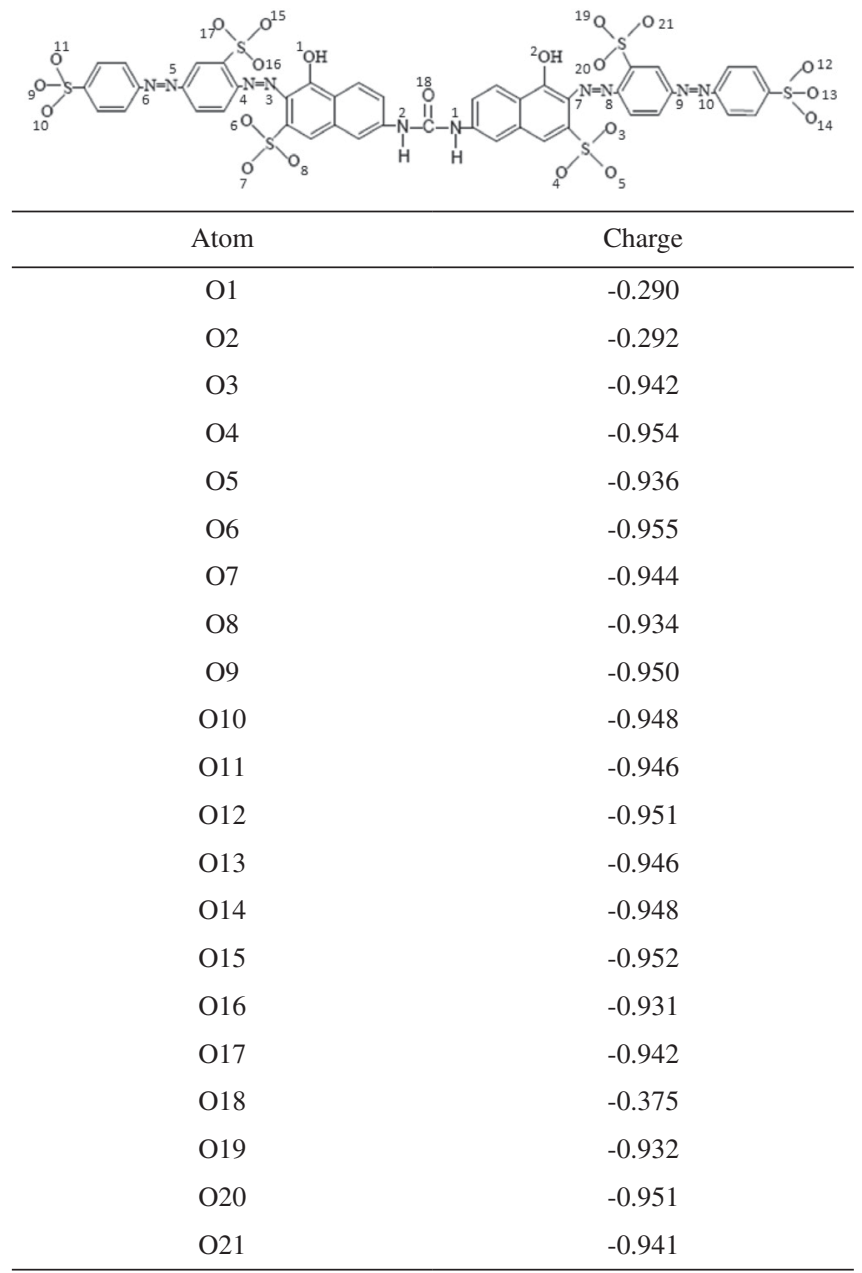

dye adsorption on the photocatalyst surface and the semiconductor concentration.

\section{ACKNOWLEDGEMENTS}

The authors thank to Fundação Araucária for financial aid (22850/2011). W. J. C. S., N. M. M., and V. S. L. N. are grateful for scholarship.

\section{REFERENCES}

1. Zollinger, H.; Color Chemistry: synthesis, properties and applications of organic dyes and pigments VCH: Weinheim, 1991.

2. Sandhu, P.; Chipman, J. K.; Mutat. Res. 1990, $240,227$.

3. Kim, S.; Park, C.; Kim, T-H.; Lee, J.; Kim, S.-W.; J. Biosci. Bioeng. 2003, 95, 102.

4. Poyatos, J. M.; Munio, M. M.; Almecija, M. C.; Torres, J. C.; Hontoria, E.; Osorio, F.; Water Air Soil Pollut. 2010, 205, 187.

5. De Jager, D.; Sheldon, M. S.; Edwards, W.; Sep. Purif. Technol. 2014, 135,135 .

6. Hoffmann, M. R.; Martin, S. T.; Choi, W.; Bahnemann, D. W.; Chem. Rev. 1995, 95, 69.

7. Konstantinou, I. K.; Albanis, T. A.; Appl. Catal., B 2004, 49, 1.

8. Gaya, U. I.; Abdullah, A. H.; J. Photochem. Photobiol., C 2008, 9, 1.

9. Legrini, O.; Oliveros, E.; Braun, A. M.; Chem. Rev. 1993, 93, 671.

10. Evgenidou, E.; Konstantinou, I.; Fytianos, K.; Poulios, I.; Albanis, T.; Catal. Today 2007, 124, 156. 
11. Michael, I.; Hapeshi, E.; Michael, C.; Fatta-Kassinos, D.; Water Res. 2010, 44, 5450 .

12. Chen, X.; Wang, W.; Xiao, H.; Hong, C.; Zhu, F.; Yao, Y.; Xue, Z.; Chem. Eng. J. 2012, 193, 290.

13. Singh, C.; Chaudhary, R.; Gandhi, K.; J. Renew. Sustain. Energy 2013, 5, 023124.

14. Haroune, L.; Salaun, M.; Ménard, A.; Legault, C. Y.; Bellenger, J.-P.; Sci. Total Environ. 2014, 475, 16

15. Daneshvar, N.; Salari, D; Khataee, A. R.; J. Photochem. Photobiol., A 2003, 157, 111.

16. Ishiki, R. R.; Ishiki, H. M.; Takashima, K.; Chemosphere 2005, 58, 1461.

17. Bizani, E.; Fytianos, K.; Poulios, I.; Tsiridis, V.; J. Hazard. Mater. 2006, 136,85 .

18. Farooq, M.; Raja, I. A.; Pervez, A.; Sol. Energy 2009, 83, 1527.

19. Lucilha, A. C.; Bonancêa, C. E.; Barreto, W. J.; Takashima, K.; Spectrochim. Acta, Part A 2010, 75, 389.

20. Parra, S.; Olivero, J.; Pulgarin, C.; Appl. Catal., B 2002, 36, 75.

21. Daneshvar, N.; Salari, D.; Khataee, A. R.; J. Photochem. Photobiol., A 2003, 157, 111.

22. Bizani, E.; Fytianos, K.; Poulios, I.; Tsiridis, V.; J. Hazard Mater. 2006, 136,85 .

23. Atkins, P.; De Paula, J.; Physical Chemistry, $10^{\text {th }}$ ed., OUP Oxford: Oxford, 2010
24. Wavefunction; Spartan v.06, Program for Structure Optimization, Inc. Irvine, USA, 2006.

25. Da Silva, W. J. C.; Da Silva, M. R.; Takashima, K.; J. Chil. Chem. Soc. $\mathbf{2 0 1 5}, 60,2749$.

26. Zielinska, B.; Grzechulska, J.; Grzmil, B.; Morawski, A. W.; Appl. Catal., B 2001, 35, L5.

27. Li, G.; Lv, L.; Fan, H.; Ma, J.; Li, Y.; Wan, Y.; Zhao, X. S.; J. Colloid Interface Sci. 2010, 348, 342.

28. Danwittayakul, S.; Jaisai, M.; Koottatep, T.; Dutta, J.; Ind. Eng. Chem. Res. 2013, 52, 13629.

29. Alzahrani, E.; Curr. Anal. Chem. 2016, 12, 465.

30. Hamadanian, M.; Sarabi, A. S.; Mehra, A. M.; Jabbari, V.; Mater. Sci. Semicond. Process. 2014, 21, 161.

31. Daneshvar, N.; Rasoulifard, M. H.; Khataee, A. R.; Hosseinzadeh, F.; J. Hazard. Mater. 2007, 143, 95.

32. Zhang, X.; Sunb, D. D.; Li, G.; Wang, Y; J. Photochem. Photobiol., A 2008, 199, 311 .

33. Niehues, E.; Scarmínio, I. S.; Takashima, K.; J. Chil. Chem. Soc. 2010 , 55,320 .

34. Zhang, Q.; Jing, Y. H.; Shiue, A.; Chang, C-T.; Chen, B-Y.; Hsueh, C.C.; J. Taiwan Inst. Chem. Eng. 2012, 43, 760.

35. Tsuji, E.; Taguchi, Y.; Aoki, Y.; Hashimoto, T.; Skeldon, P.; Thompson, G. E.; Habazaki, H; Appl. Surf. Sci. 2014, 301, 500. 